\title{
Experimental Study on Immersion Effects of Pressure Water on the Tensile Characteristics of Sandstone Samples
}

\author{
Dawei Yin (D), Shaojie Chen (D), Bing Chen (D), Rui Liu, and Faxin Li \\ State Key Laboratory of Mine Disaster Prevention and Control, Shandong University of Science and Technology, \\ Qingdao 266590, China \\ Correspondence should be addressed to Shaojie Chen; csjwyb@163.com and Bing Chen; cdbakdw@163.com
}

Received 21 December 2020; Revised 12 January 2021; Accepted 18 January 2021; Published 1 February 2021

Academic Editor: Feng Xiong

Copyright (c) 2021 Dawei Yin et al. This is an open access article distributed under the Creative Commons Attribution License, which permits unrestricted use, distribution, and reproduction in any medium, provided the original work is properly cited.

\begin{abstract}
In this study, Brazilian splitting tests were conducted on sandstone samples subjected to drying and immersing at water pressures of 0,1 , and $3 \mathrm{MPa}$ (immersion duration of $120 \mathrm{~h}$ ). Investigation of the immersion effects of pressure water on the tensile characteristics of the samples revealed that their tensile strengths decreased with the immersion water pressure. Relative to a sandstone sample subjected to drying alone, immersing at water pressures of 0,1 , and $3 \mathrm{MPa}$ reduced the tensile strength by $12.96 \%, 19.03 \%$, and $30.16 \%$, respectively. Although the immersed samples experienced splitting failure indicative of obvious brittle failure characteristics, decreases in the postpeak stress reduction rate with immersion water pressure revealed that the intensity of brittle failure weakened with pressure. Based on the obtained data, the deformation evolution process of the sandstone samples could be divided into five stages: deformation adjustment, formation of local deformation zones, local deformation zone propagation, failure surface formation, and sample failure. The water pressure aggravated the physicochemical reactions between water and the hydrophilic minerals in the sandstone, promoting argillisation, dissolution, and loss of hydrophilic minerals and interparticle cementitious materials. As a result of these immersion micromechanisms, the deterioration of the sandstone samples increased with the immersion water pressure, with the average porosities of the fracture surfaces at 0,1 , and $3 \mathrm{MPa}$ increasing by $142.86 \%, 368.37 \%$, and $593.88 \%$, respectively, relative to the dried sample. As a result of these morphological changes, the sandstone samples subjected to water pressure immersion failed at small axial stresses with low levels of applied mechanical energy.
\end{abstract}

\section{Introduction}

Rock is an important building material used in many engineering applications, including water conservancy and hydropower engineering and tunnel engineering [1-9]. In such applications, the rock will inevitably be immersed in water for short to long durations [10-15], altering its mechanical properties. The tensile strength of rock is much lower than its compressive strength, and water-bearing rock is often subjected to tensile failure under loading [16-19]. Therefore, it is important to investigate the effects of water on the tensile characteristics of rock.

Many studies have been carried to determine these effects. You et al. [18] investigated the tensile strengths of rock discs and rings under dry and saturated conditions. Deng et al. [16] analysed the effects of moisture content on the splitting tensile strength of layered sandstone. Vásárhelyi and Ván [20] proposed a method for estimating the sensitivity of sandstone rocks to water content based on published data. Inada and Yokota [17] investigated the tensile characteristics of dry and $70 \%$ saturated rocks under lowtemperature $\left(-160\right.$ to $\left.+20^{\circ} \mathrm{C}\right)$ conditions and freeze-thaw cycling, revealing that tensile strength decreased as temperature decreased. Wang et al. [21] performed Brazilian splitting tests on rocks with different moisture contents at different temperatures to determine the superposition effects of these factors on the tensile strength of the rock. Zhu et al. [22] investigated the tensile strengths of rock under dry, saturated, and long-term immersion conditions. Ma et al. [23] analysed the tensile strength and failure characteristics of coal samples immersed for different lengths of time and found that the tensile strengths first decreased and then 


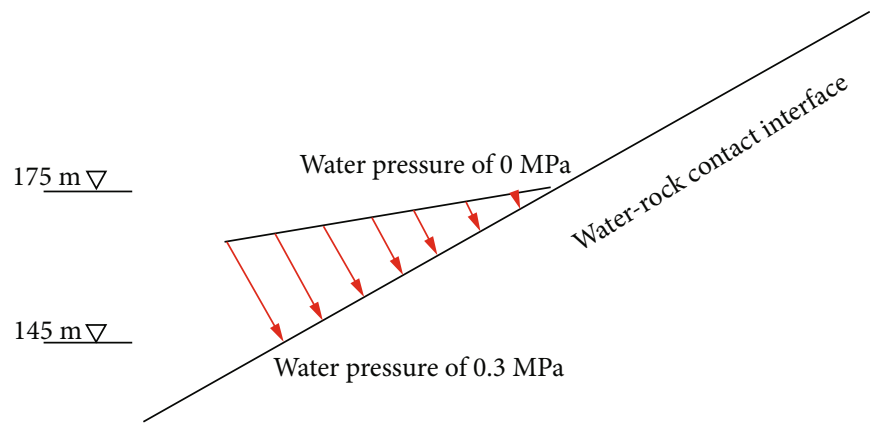

FIGURE 1: Water pressure distribution in fluctuating zone of Three Gorges dam bank slide [20].

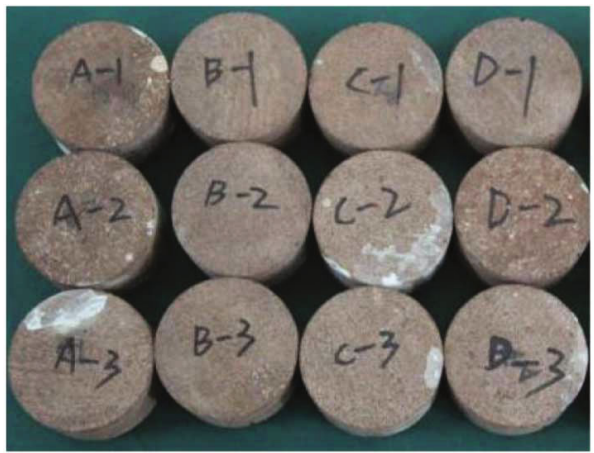

FIGURE 2: Sandstone samples.

stabilised as the immersion time increased. Wen et al. [24] studied the propagation mechanisms of microcracks in rock subjected to Brazilian splitting and noted that the coupling effects of intergranular and transgranular particle fractures led to the eventual tensile fracturing of the rock. Bresser et al. [25] quantitatively analysed the microstructures of marble fracture surfaces with different water contents and established a criterion for evaluating the effects of water on the evolution of damage in such microstructures.

The investigations discussed above were necessary to understand the influences of water on the tensile characteristics of rock. In general, water pressure will be present within the environment of an engineering rock mass [26, 27]. For example, rocks located in different regions within a reservoir dam will be affected by different water pressures (Figure 1 [28]). Zhang et al. [28] investigated the long-term stability of the bank slide fluctuation zone (145-175 m) of the Three Gorges dam in terms of water pressure fluctuation and water-rock interaction. Liu and Yan [29] conducted triaxial compression and triaxial creep tests on rocks under the coupling action of axial and hydraulic pressure to assess the fracture surface microdamage mechanism. Despite this body of research, few studies to date have focused on the immersion effects of pressure water on the mechanical properties of rock. To address this gap in the literature, we performed Brazilian splitting tests on dried sandstone and sandstone samples immersed at water pressures of 0,1 , and $3 \mathrm{MPa}$, respectively, in this study. The immersion effects of pressure water on the tensile characteristics of the sandstone samples, including their tensile strengths, stress-time curves, energies, deformation evolution, and fracture surface microcharacteristics, were investigated, respectively.

\section{Experimental Procedure}

2.1. Sample Preparation. Sandstone is common in engineering application. Therefore, the samples used in the tests were compact sandstones obtained from the Dingbao Sandstone Factory in Linyi City, Shandong Province, China. The sandstones comprised maroon, fine-grained (average grain size of $0.174 \mathrm{~mm}$ ) rock material with a bulk density of $2686 \mathrm{~kg} / \mathrm{m}^{3}$. This type of sandstone primarily comprises quartz and feldspar, with a small amount of hematite and mica. The processes used to prepare the sandstone samples are described as follows.

Sandstone blocks were first drilled into cylindrical samples with diameters of $50 \mathrm{~mm}$ using a ZS-50/100 automatic coring machine (Jiangyan Xingguang Instrument Equipment Factory). The cylindrical samples were then cut to heights of $25 \mathrm{~mm}$ by a DQ1-4 stone sawing machine (Jiangyan Xingguang Instrument Equipment Factory). To meet the experimental requirements, both ends of the cylinder samples were flattened and smoothed by using an SCM-200 stone grinding machine (Cangzhou Longhui Road Railway Test Equipment Factory). The parallel misalignment of each sample's ends had to be less than $0.005 \mathrm{~cm}$ with a dimensional deviation of less than $0.02 \mathrm{~cm}$ [30]. The prepared sandstone samples used for Brazilian splitting testing are shown in Figure 2.

The twelve sandstone samples were categorised into groups $\mathrm{A}, \mathrm{B}, \mathrm{C}$, and $\mathrm{D}$, respectively. To analyse the immersion effects of water pressure on the tensile characteristics of samples, one group (A) was subjected to drying as a control and groups $\mathrm{B}, \mathrm{C}$, and $\mathrm{D}$ were immersed in water at pressures of 0,1 , and $3 \mathrm{MPa}$ (immersion duration of $120 \mathrm{~h}$ ), respectively.

2.2. Testing System. The Brazilian splitting test setup is shown in Figure 3. It comprises a loading system, a water immersion system, a digital speckle system, and a scanning electron microscope (SEM). To facilitate the analysis of the experimental results, the loading and digital speckle systems were synchronised to produce simultaneous timestamps.

The loading system was a servo-controlled testing device (AG-X250, SHIMADZU) with a maximum test load of $250 \mathrm{kN}$. A double screw loading structure was used to achieve 


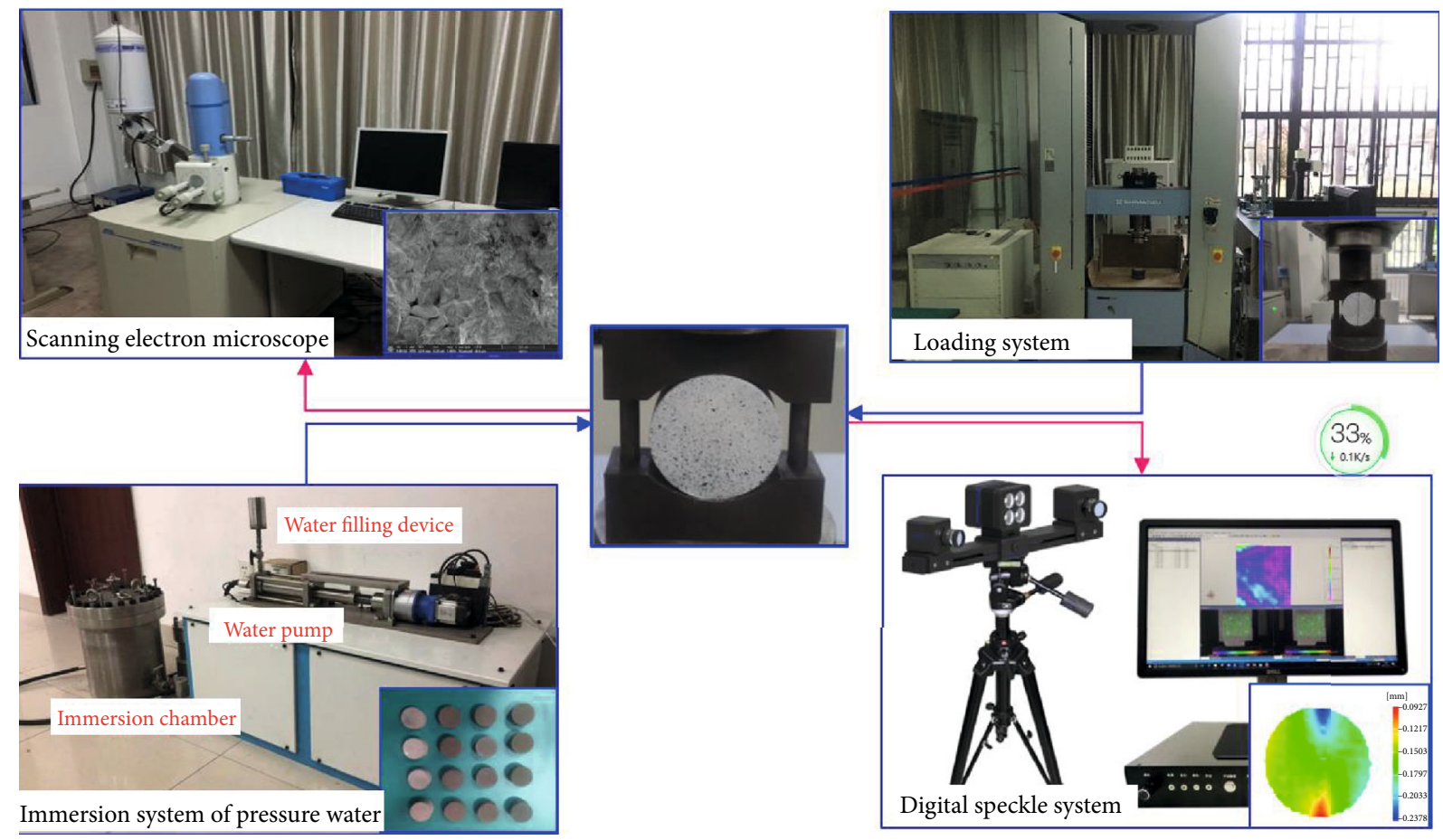

FIGURE 3: System for the Brazilian splitting testing of sandstone samples.

the working flexibility needed by the testing system to execute conventional compression, tensile, and other mechanical testing [31, 32]. In the experiments, a stress loading control method with a loading rate of $0.05 \mathrm{kN} / \mathrm{s}$ was adopted.

The water pressure immersion system primarily comprised an immersion chamber, water filling device, and water pump. A maximum water pressure of $30 \mathrm{MPa}$ could be achieved using the system. The immersion chamber was cylindrical with external and internal diameters of 300 and $250 \mathrm{~mm}$, respectively. The experimental immersion water pressure settings were 0,1 , and $3 \mathrm{MPa}$, respectively, with an immersion time of $120 \mathrm{~h}$ in each case.

The digital speckle system was an XTDIC strain measurement and analysis system provided by Xi'an Xintuo 3D Optical Measurement Technology Co., Ltd. The hardware system comprised a camera, image acquisition card, monitor, computer, and A/D card. The camera was used to capture surface images of the sandstone samples during the Brazilian splitting testing. These images were transferred to the image card for digitisation and stored in a computer for processing. The monitor displayed real-time images of samples over the duration of testing. The computer served as the control core of the overall system, sending instructions to coordinate the functioning of each component, saving and processing images, and outputting the final results. The software system was used to process speckle images collected during the experiment to obtain the required deformation field, including the displacement, strain, and correlation coefficient distribution fields. During the testing, the image data acquisition speed was 15 frames/s.

The SEM was a JSM-6510lv high- and low-vacuum device. The accelerating voltage of the SEM was $0.530 \mathrm{kV}$, and the high- and low-vacuum resolutions were 3 and
$15 \mathrm{~nm}$, respectively. Each sample was magnified by a factor of 50-300000.

2.3. Testing Method. The sandstone samples were first dried using a drying oven at a temperature of $105^{\circ} \mathrm{C}$ for $24 \mathrm{~h}$. Three samples were then selected as group $\mathrm{A}$, and the remainder, corresponding to groups $\mathrm{B}, \mathrm{C}$, and $\mathrm{D}$, were immersed in water for $72 \mathrm{~h}$ to achieve a water-saturated state. The saturated sandstone samples were then immersed in water at pressures of 0,1 , and $3 \mathrm{MPa}$, respectively, by using the pressurised immersion system. Prior to Brazilian splitting tests, an artificial speckle field was constructed on the surface of each sandstone sample by using black and white spray paint. These fields were used to monitor the deformation characteristics of the sandstone samples. After samples' failure, the SEM was used to analyse the microcharacteristics of the failure surfaces to reveal its tensile characteristics.

\section{Results}

3.1. Tensile Strength Characteristics of Sandstone Samples. The tensile strength $\sigma_{t}$ of a sandstone sample can be obtained by solving the following equation [33-35]:

$$
\sigma_{t}=\frac{2 P}{\pi D H}
$$

where $P$ is the ultimate axial load at failure of the sandstone sample and $D$ and $H$ are the diameter $(50 \mathrm{~mm})$ and thickness ( $25 \mathrm{~mm}$ ) of the sample, respectively. Table 1 lists values of $\sigma_{t}$ of the groups A, B, C, and D sandstone samples.

It can be seen from the table that the values of $\sigma_{t}$ differed by group and sample, indicating that the immersion water 
TABLE 1: Tensile strength test results.

\begin{tabular}{lccc}
\hline Immersion condition & Sample No. & $P / \mathrm{kN}$ & $\sigma_{t} / \mathrm{MPa}$ \\
\hline \multirow{4}{*}{ Dry } & A-1 & 9.83 & 5.00 \\
& A-2 & 8.81 & 4.49 \\
& Average value & 9.70 & 4.94 \\
& B-1 & 8.55 & 4.36 \\
Immersed in water at & B-2 & 8.64 & 4.40 \\
pressure of 0 MPa & B-3 & 8.13 & 4.14 \\
& Average value & 8.44 & 4.30 \\
Immersed in water at & C-1 & 7.72 & 3.93 \\
pressure of 1 MPa & C-2 & 7.97 & 4.06 \\
& C-3 & 7.87 & 4.01 \\
& Average value & 7.85 & 4.00 \\
Immersed in water at & D-1 & 7.10 & 3.61 \\
pressure of $3 \mathrm{MPa}$ & D-2 & 6.64 & 3.38 \\
& D-3 & 7.38 & 3.36 \\
& Average value & 7.04 & 3.45 \\
\hline
\end{tabular}

pressure affected the tensile strengths of sandstone samples. To more quantitatively analyse this effect, the values of $\sigma_{t}$ were compared in Figure 4.

The group A samples had the highest $\sigma_{t}$ values, with an average group value of $4.94 \mathrm{MPa}$. The group D samples had the lowest $\sigma_{t}$ values, with an average of $3.45 \mathrm{MPa}$. Increasing the immersion water pressure caused the value of $\sigma_{t}$ to gradually decrease, with the average values of $\sigma_{t}$ for groups $\mathrm{B}, \mathrm{C}$, and D decreasing by $12.96,19.03$, and $30.16 \%$, respectively, relative to group $\mathrm{A}$. These results reveal that the pressure induced by immersion in water weakened the tensile strength of the sandstone samples, with a weakening effect that increased with the water pressure. The weakening was primarily induced by the increased efficiency of water-rock interaction under immersion; that is, the water pressure aggravated the water-rock interaction, as will be further analysed in Discussion.

\subsection{Stress-Time Curve Characteristics of Sandstone Samples.} Figure 5 shows typical stress-time curves of sandstone samples under different immersion conditions. It can be seen that the stress-time curves of the four groups of samples are all similar. In each case, the samples are weakened by three stages: an initial compaction stage, a linear elastic stage, and a postpeak failure stage. As shown in Figure 6, the samples experienced splitting failure, producing obvious brittle failure characteristics, and the corresponding postpeak stress-time curve of the sandstone samples dropped sharply.

To analyse the intensities of brittle failure in the sandstone samples, we calculated their postpeak stress reduction rates by using the following formula:

$$
\delta=\left|\frac{\sigma_{p}-\sigma_{i}}{t_{p}-t_{i}}\right|,
$$

where $\delta$ is the postpeak stress reduction rate, $\sigma_{p}$ is the peak stress, $\sigma_{i}$ is the axial stress at the conclusion of loading, $t_{p}$ is the time at which peak stress occurs, and $t_{i}$ is the time at which the end of loading occurs. Figure 7 shows the postpeak stress reduction rates of the sandstone samples.

It is seen from the figure that the $\delta$ values of the group A sandstone samples were the largest among the four groups, with an average value of $9.97 \mathrm{MPa} / \mathrm{s}$, indicating that this group of sandstone samples experienced the most serious brittle failure. The values of $\delta$ for the group D sandstone samples were the smallest, with an average value of $2.49 \mathrm{MPa} / \mathrm{s}$, indicating the least degree of brittle failure. As the immersion water pressure increased from 0 to $3 \mathrm{MPa}$, the values of $\delta$ gradually decreased; relative to the group $\mathrm{A}$ samples, the average values of $\delta$ for groups $\mathrm{B}, \mathrm{C}$, and $\mathrm{D}$ were reduced by $27.88,47.19$, and $75.07 \%$, respectively. Overall, the intensity of sandstone sample brittle failure was reduced as the immersion water pressure rose.

3.3. Energy Characteristics of Sandstone Samples. Tavallali and Vervoort [35] developed a method for calculating the mechanical energy $(W)$ applied to a rock sample by a testing machine:

$$
W=\frac{1}{2} P S,
$$

where $P$ is the axial force of sandstone failure and $S$ is the axial displacement at the ultimate axial stress. The values of $W$ for the four sandstone samples are listed in Table 2.

It is seen from the table that the values of $W$ differ by sample, indicating that the pressure of the water in which the samples were immersed affected their energy characteristics. To quantitatively analyse these effects, the values of $W$ are compared in Figure 8.

The group A values of $W$ were the largest, with an average value of $1.95 \mathrm{~J}$, whereas group $\mathrm{D}$ had the smallest values, with an average value of $1.95 \mathrm{~J}$. As the water pressure increased, the values of $W$ gradually decreased; relative to the dry-treated group A samples, groups B, C, and D had average values that were reduced by $21.03,34.36$, and $38.46 \%$, respectively.

Damage and failure of coal or rock samples during loading are understood to be instability phenomena driven by energy. It will undergo instability and failure when the energy input reaches the sample's energy storage limit. In the stress experiments carried out in this study, the $W$ values of the sandstone samples decreased as the immersion water pressure increased, indicating that their energy storage capacities weakened as the water pressure increased. As a result, the sandstone samples (group A samples) with relatively high energy storage capacities failed at large axial stresses, indicating that they had relatively high tensile strengths. By contrast, the sandstone samples (group D samples) with relatively weak energy storage capacities failed at small axial stresses, indicating that they had low tensile strengths. These results confirmed the accuracy of the immersion analysis results. 


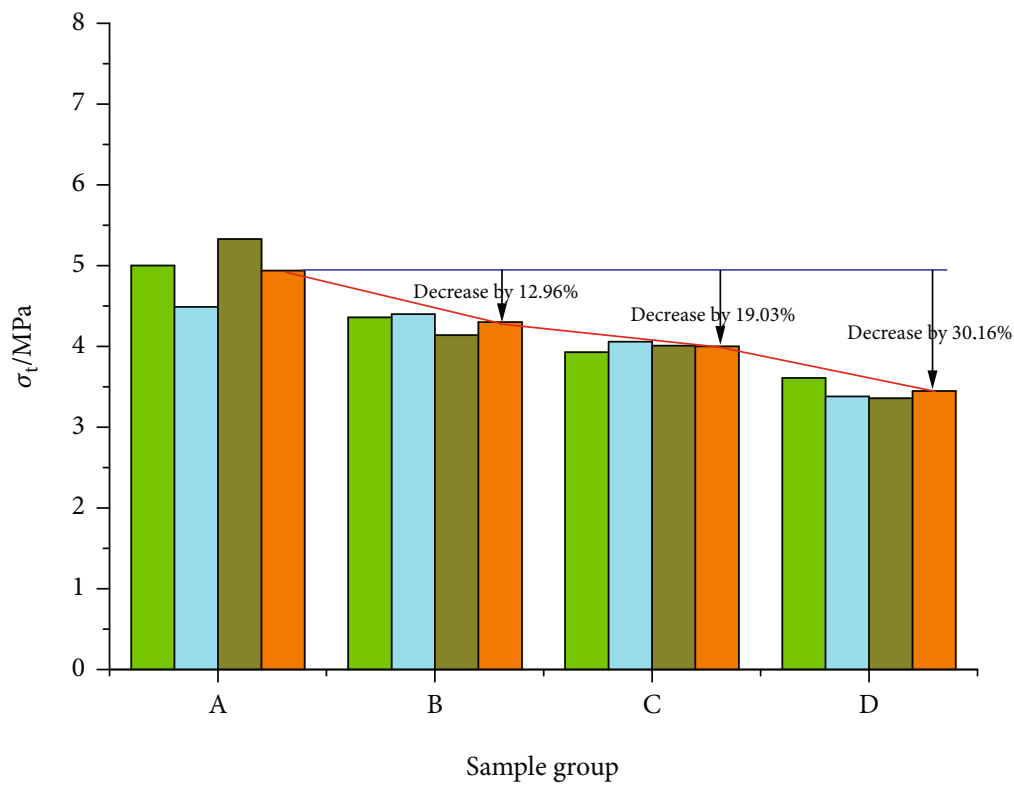

$\square \sigma_{\mathrm{t}}$ of No. 1 sample in each group $\sigma_{\mathrm{t}}$ of No. 2 sample in each group

$\sigma_{\mathrm{t}}$ of No. 3 sample in each group Average $\sigma_{\mathrm{t}}$ of each group

FIgURE 4: Comparison of sandstone sample tensile strengths.

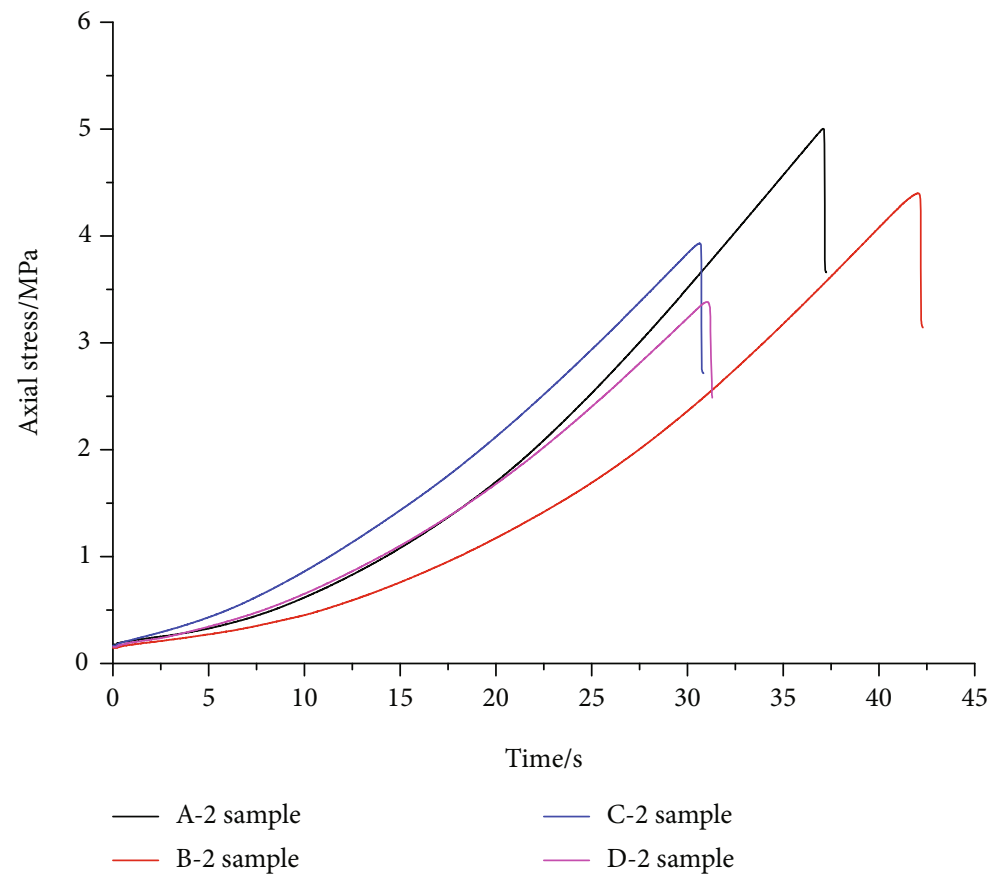

Figure 5: Typical stress-time curves of sandstone samples.

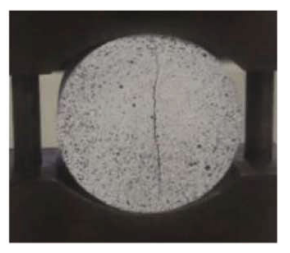

(a) Sample A-2

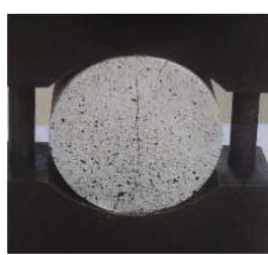

(b) Sample B-2

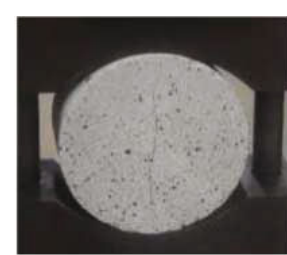

(c) Sample C-2

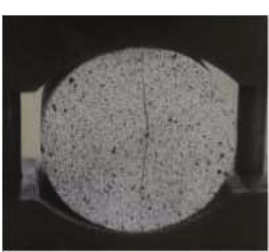

(d) Sample D-2

FIGURE 6: Sandstone sample macrofailure. 


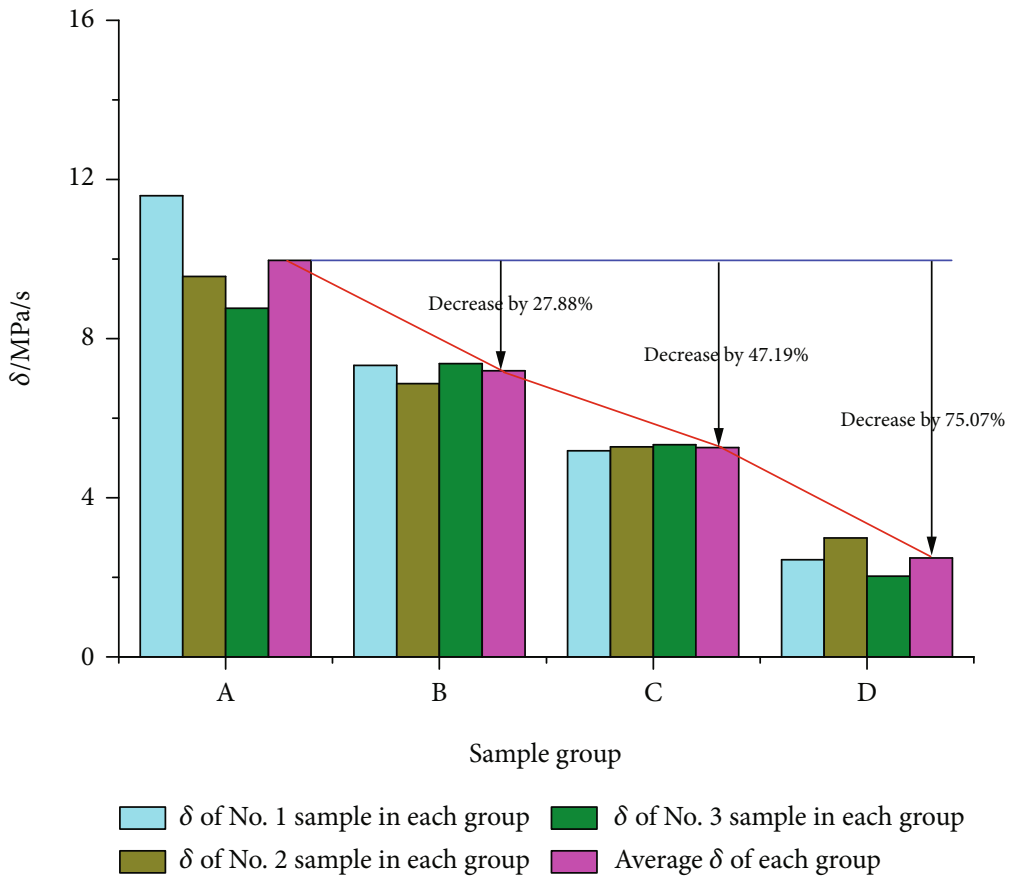

FIgURE 7: Postpeak stress reduction rates of sandstone samples.

TABLE 2: Mechanical energies applied to sandstone samples.

\begin{tabular}{lcc}
\hline Immersion condition & Sample No. & W/J \\
\hline \multirow{2}{*}{ Dry } & A-1 & 1.82 \\
& A-2 & 1.68 \\
& A-3 & 2.34 \\
& Average value & 1.95 \\
Immersion in water at pressure of $0 \mathrm{MPa}$ & B-1 & 1.47 \\
& B-2 & 1.82 \\
& B-3 & 1.33 \\
Immersion in water at pressure of $1 \mathrm{MPa}$ & Average value & 1.54 \\
& C-1 & 1.18 \\
& C-2 & 1.33 \\
& Average value & 1.28 \\
Immersion in water pressure at of $3 \mathrm{MPa}$ & D-1 & 1.23 \\
& D-2 & 1.03 \\
& D-3 & 1.34 \\
& Average value & 1.20 \\
\hline
\end{tabular}

3.4. Deformation Evolution Characteristics of Sandstone Samples. Figure 9 shows the deformation evolution processes of sandstone samples A-2, B-2, C-2, and D-2, respectively, during the Brazilian splitting tests.

It can be seen from the figure that the deformation evolution processes of all samples were similar to each other. The deformation evolution processes can be divided into five stages: deformation adjustment, production of local deformation zones, propagation of local deformation zones, failure surface formation, and sample failure.
The sandstone samples contained natural defects that led to the formation of microcracks and dissolution pores following water treatment. In the deformation adjustment stage, natural cracks and newly formed cracks and pores closed under loading, and the sandstone particles dislocated to adapt to the increase on axial stress. As the immersion water pressure increased, the water-rock interaction was strengthened, and as a result, the number of new defects increased, enhancing the dislocations between particles owing to their low mutual adhesion. As a result, the deformation in this stage was affected by the natural defects in the sandstone, increased with the immersion water pressure.

As the axial stress increased, local deformation zones appeared in the upper and lower ends of the sandstone samples. The deformations in the upper local deformation zones were larger than those in the lower local deformation zones. As the axial stress increased further, the local deformation zones became more obvious and began to propagate toward the central area along the centre line of the samples. The local deformation zone propagation stage was the longest stage of loading process and, as a result of water-rock interaction, decreased in duration as the immersion water pressure increased. Finally, the upper and lower local deformation zones connected and failure surfaces form, leading to failure of the sandstone samples.

3.5. Microcharacteristics of Fracture Surfaces on Sandstone Samples. The water-rock interactions constitute the degradation of macromechanical properties induced by the variations in microstructures. We used the SEM system to analyse the microcharacteristics of the fracture surfaces on the sandstone samples. Figure 10 shows SEM images of fracture surfaces on samples A-2, B-2, C-2, and D-2 following the Brazilian splitting tests. 


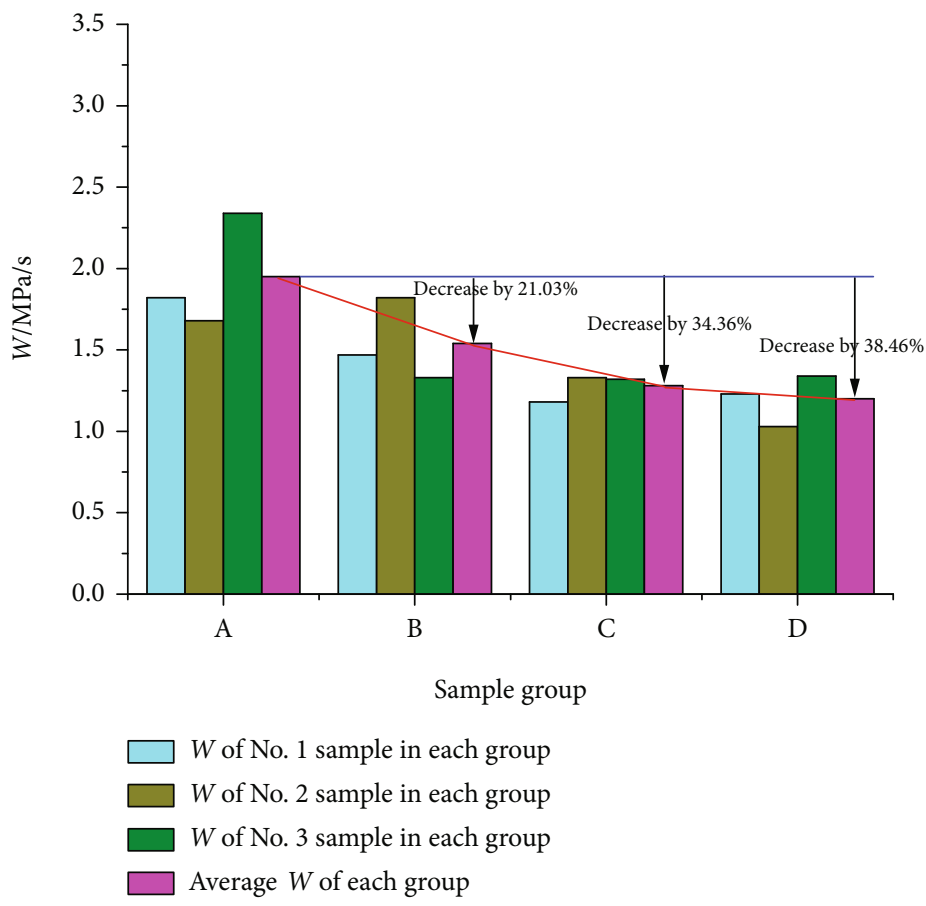

Figure 8: Comparison of sandstone sample $W$ values.

In Figure 10(a), the fracture surface particles on sandstone sample A-2 were clear. The fracture surface was quite compact and homogeneous, and there were few microcracks or pores. Because the cementation force between particles was relatively high, the corresponding tensile strength was relatively high.

After pressure water treatment, the physicochemical reactions between hydrophilic minerals of the sandstone sample and water were strengthened. The hydrolytic argillisation of the hydrophilic minerals and cementitious materials between particles were also enhanced. As a result, the fracture surfaces of samples B-2, C-2, and D-2 were very loose, as shown in Figures 10(b)-10(d), respectively. There were many microcracks and dissolution pores. As the immersion water pressure increased, the fracture surface morphology gradually developed into a honeycomb.

\section{Discussion}

The internal cohesive forces of sandstone samples played an important role in their mechanical properties. The analysis of the effects of pressurised water on the cohesive forces revealed the mechanism through which the water pressure deteriorated the mechanical properties of the samples.

The internal cohesive forces of a sandstone sample can be simplified into the internal cohesive force of an individual particle $\left(F_{1}\right)$, the cementation force between particles $\left(F_{2}\right)$, the surface friction force between particles $\left(F_{3}\right)$, and the occlusal resistance force between particles $\left(F_{4}\right)$, as shown in Figure 11 [36].

The primary components of the sandstone samples were clay and detrital minerals. Physicochemical reactions between hydrophilic minerals and water caused the particles to become filled with water molecules, altering the porosity and microstructures of the particles. At the same time, the hydrophilic and cementitious materials between particles underwent hydrolysis and argillisation, causing them to dissolve and become lost in the water. As a result, the sample particle sizes decreased along with the interparticle contact areas and the adhesion between particles was weakened (Figure 11), causing the value of $F_{1}$ to drop sharply. The loss of cementitious materials between particles also caused a decrease in $F_{2}$. Owing to the smoothness of the particle surfaces and the increase in the numbers of pores between particles, the values of $F_{3}$ and $F_{4}$ decreased. Because the effects of water pressure on the cohesive forces in the sandstone samples increased with the immersion pressure, increasing the pressure enhanced the deterioration of the samples' mechanical properties.

The analysis above indicates that the internal cohesive forces of the sandstone samples were directly affected by the dissolution and loss of mineral components, which in turn increased the number of pores and microcracks in the samples. To quantitatively analyse the deterioration effects of immersion water pressure on the mechanical properties of the sandstone samples, the porosities of their fracture surfaces were calculated using the PCAS software package [37]. The full name of PCAS software is called Particles (Pores) and Cracks Analysis System. The software is mainly used for the identification and quantitative analysis of pore system and fracture system. It has been applied to more than twenty universities and research institutions at home and abroad.

SEM images of the fracture surfaces were first converted into binary images using multicolor segmentation and spot removal operations, as shown in Figure 12. The PCAS 


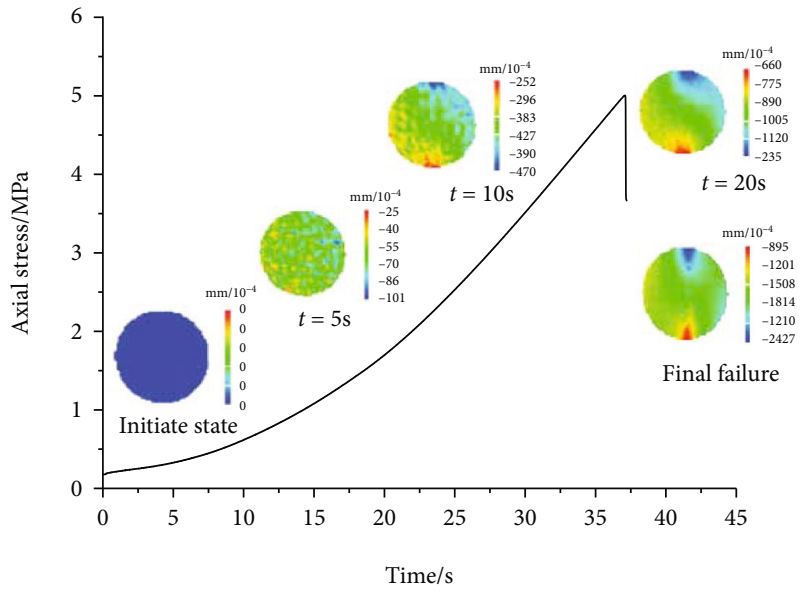

(a) Sandstone sample A-2

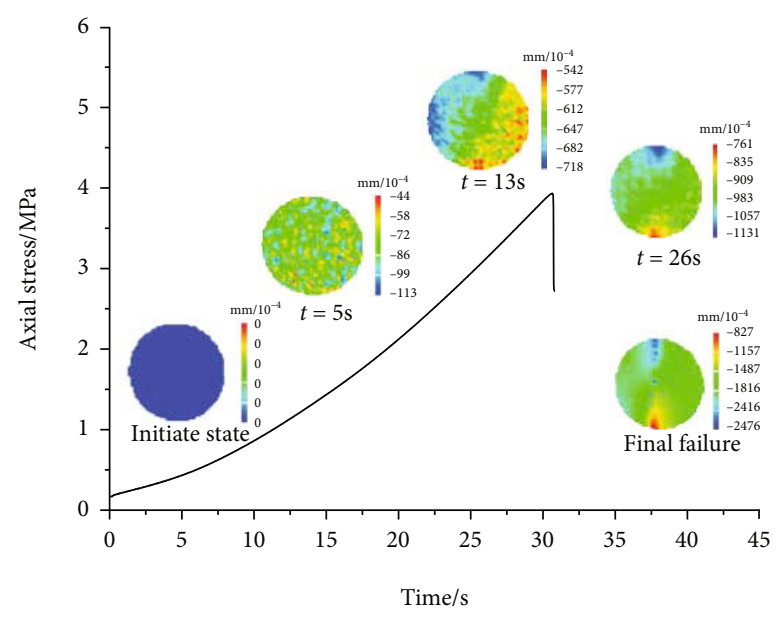

(c) Sandstone sample C-2

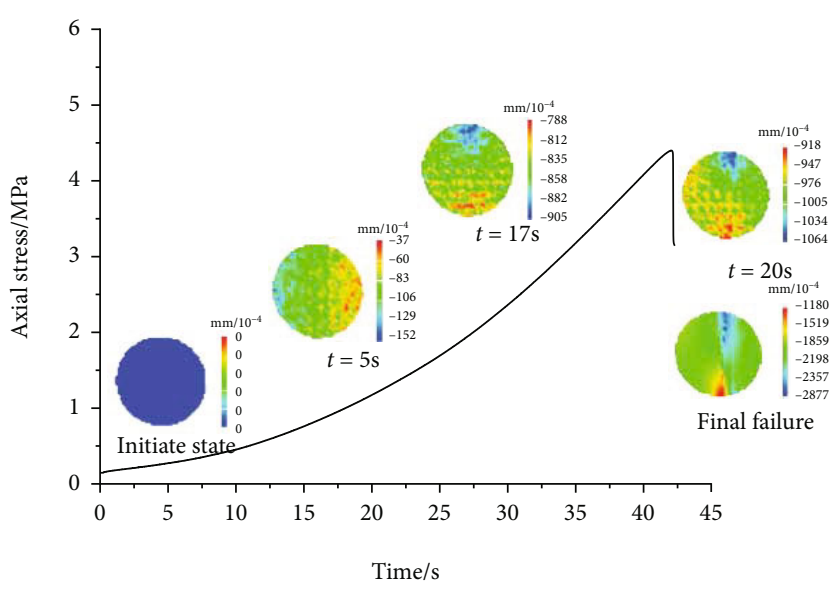

(b) Sandstone sample B-2

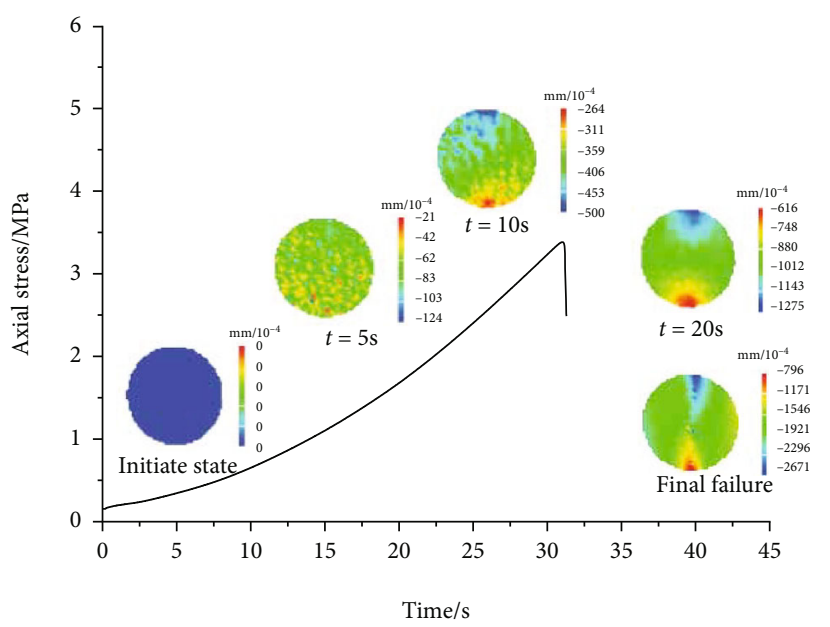

(d) Sandstone sample D-2

FIgURE 9: Sandstone sample deformation evolution processes.

software was then used to identify the pores and particles of the fracture surfaces [38] to obtain the surfaces' porosities. The average porosities of the fracture surfaces on samples A-2, B-2, C-2, and D-2 are compared in Figure 13.

The A-2 and D-2 samples had the smallest and largest average porosities $(0.98 \%$ and $6.80 \%$, respectively). As the immersion water pressure increased, the average porosity of the fracture surface increased. Relative to sample A-2, the average fracture surface porosities of samples B-2, C-2, and D-2 were enhanced by $142.86,368.37$, and $593.88 \%$, respectively. This suggests that the number of pores and microcracks in the sandstone samples increased with the immersion water pressure, i.e., that the internal cohesive forces within the samples were weakened in proportion to the immersion water pressure.

\section{Conclusions}

In this study, Brazilian splitting tests were conducted on sandstone samples subjected to drying and immersion at water pressures of 0,1 , and $3 \mathrm{MPa}$ (immersion duration of $120 \mathrm{~h}$ ). The immersion effects of pressure water on the tensile strengths, stress-time curves, energies, deformation evolution, and microcharacteristics of the samples' fracture surfaces were investigated. The main conclusions are as follows:

(1) Immersion in pressurised water weakened the tensile strengths of the sandstone samples, with the weakening effect increasing with the water pressure. Relative to a sandstone sample subjected to drying alone, the tensile strengths of samples subjected to immersion at pressures of 0,1 , and $3 \mathrm{MPa}$ were reduced by $12.96 \%, 19.03 \%$, and $30.16 \%$, respectively

(2) All sandstone samples experienced splitting failure with obvious brittle failure characteristics. Relative to the samples subjected to drying, the average postpeak stress reductions under immersion at water pressures of 0,1 , and $3 \mathrm{MPa}$ were reduced by $27.88 \%, 47.19 \%$, and $75.07 \%$, respectively. The intensity of brittle failure decreased with the immersion water pressure

(3) The mechanical energy needed to cause failure in the sandstone samples decreased with the immersion 


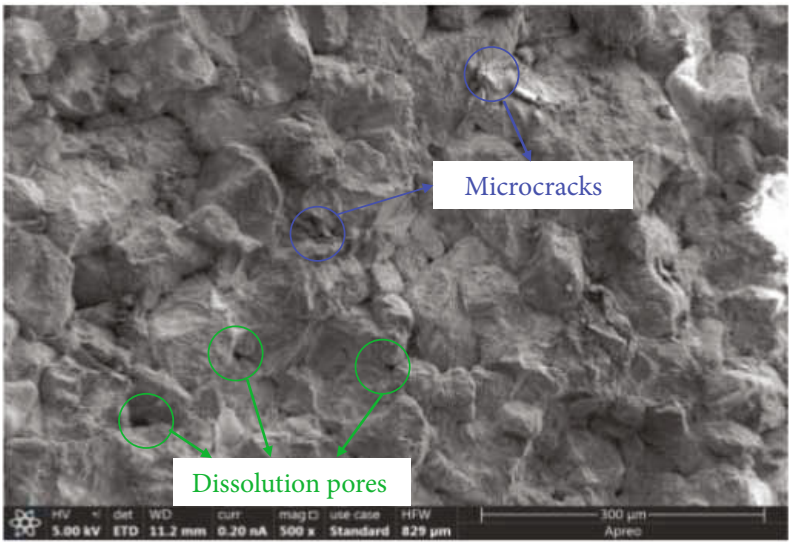

(a) Sample A-2

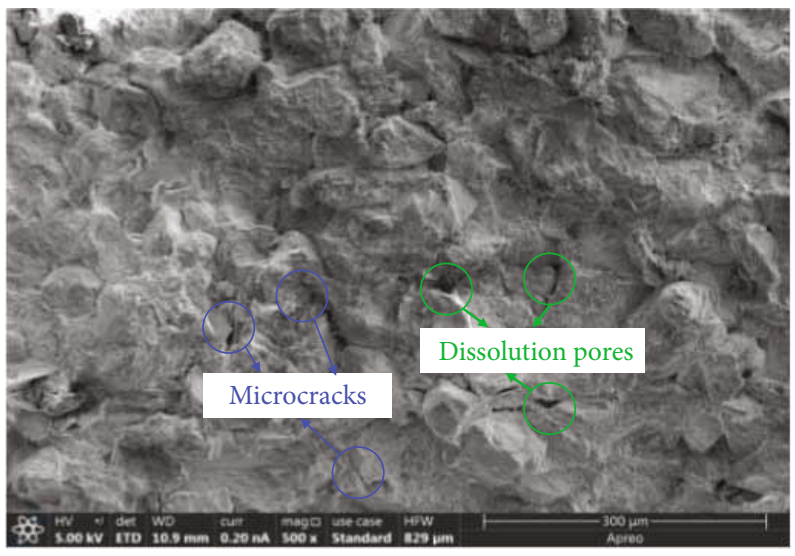

(c) Sample C-2

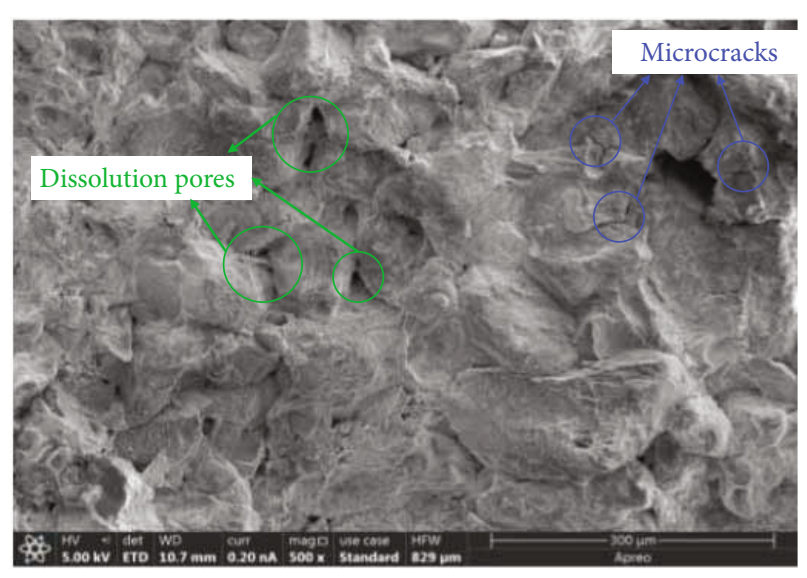

(b) Sample B-2

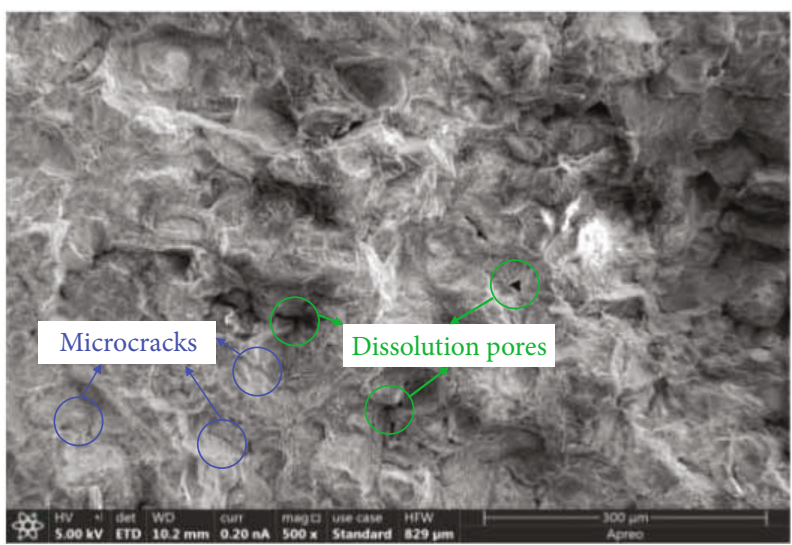

(d) Sample D-2

FiguRE 10: SEM photos of fracture surfaces on sandstone samples.
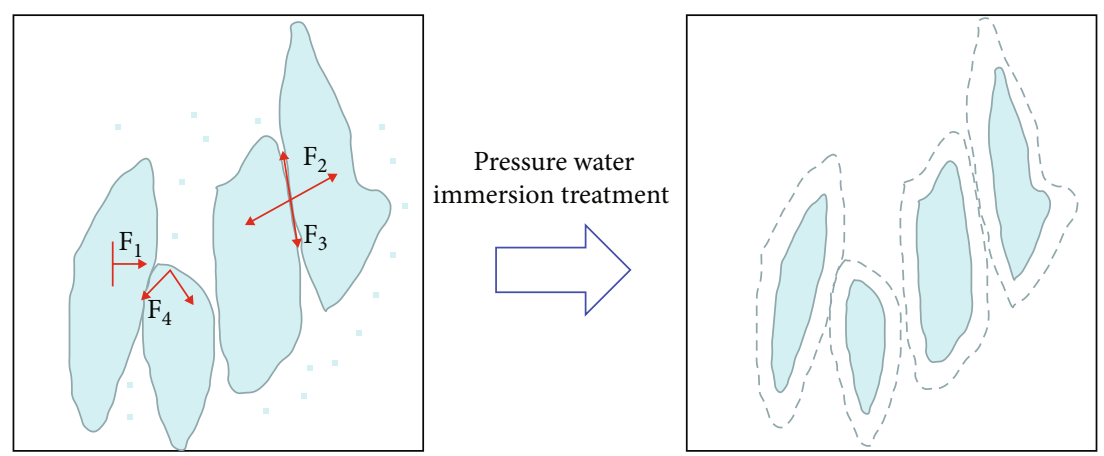

FIGURE 11: Diagram of deterioration of sandstone sample under pressurised water immersion [27].

water pressure. Relative to the dried samples, the average mechanical energies applied to the immersed samples subjected to pressures of 0,1 , and $3 \mathrm{MPa}$ were reduced by $21.03 \%, 34.36, \%$, and $38.46 \%$, respectively

(4) The deformation evolution processes of a sandstone sample can be divided into five stages: deformation adjustment, local deformation zone creation, local deformation zone propagation, failure surface formation, and sample failure

(5) The pressure of the water in which the samples were immersed aggravated the physicochemical reactions between water and hydrophilic minerals in the samples, promoting argillisation, dissolution, and loss of hydrophilic minerals and cementitious materials between particles. This led to decreases in particle 

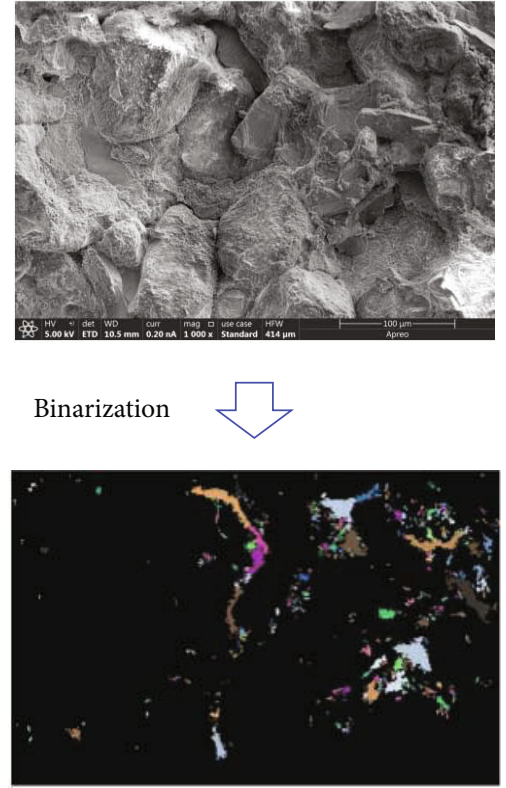

FIGURE 12: Binary image of fracture surface on sandstone sample.

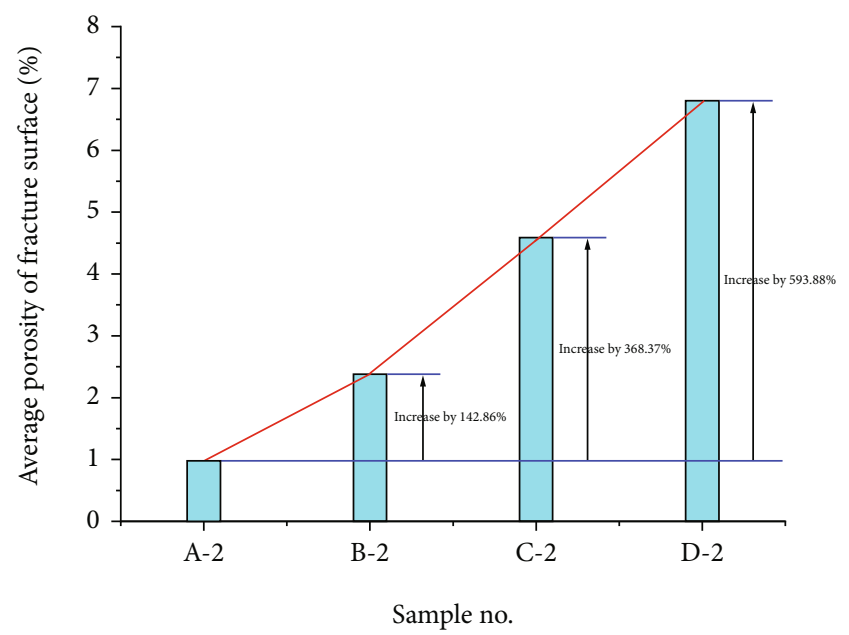

Figure 13: Comparison of average porosities of sandstone sample fracture surfaces.

size and contact surfaces, enhancements in the particle surface smoothness, and deterioration of the mechanical properties of particle surface attachment

(6) The deterioration in the sandstone samples became stronger as the immersion water pressure increased. Relative to the dried samples, the average porosities of the fracture surfaces in the samples subjected to water pressures of 0,1 , and $3 \mathrm{MPa}$ increased by $142.86 \%, 368.37 \%$, and $593.88 \%$, respectively

The rock masses of reservoirs with different water levels bear different water pressures. The experimental results on tensile properties of sandstones under three kinds of water pressures obtained in this paper have guiding significance for engineering applications such as dams and underground reservoirs. In the later work, we will further explore the influ- ence of water pressure immersion on other mechanical properties of sandstones.

\section{Data Availability}

The data used to support the findings of this study are included in the article.

\section{Conflicts of Interest}

The authors declare that they have no conflicts of interest.

\section{Acknowledgments}

This work was supported by the National Science Foundation of China (Nos. 51904167 and 52074169), the Taishan Scholars Project, the Taishan Scholar Talent Team Support Plan for Advantaged and Unique Discipline Areas, the SDUST Research Fund, and the Open Research Fund for the Key Laboratory of Safety and High-efficiency Coal Mining (No. JYBSYS2019201).

\section{References}

[1] L. J. Ma, X. Y. Liu, M. Y. Wang et al., "Experimental investigation of the mechanical properties of rock salt under triaxial cyclic loading," International Journal of Rock Mechanics and Mining Sciences, vol. 62, pp. 34-41, 2013.

[2] M. N. Bagde and V. Petroš, "Fatigue properties of intact sandstone samples subjected to dynamic uniaxial cyclical loading," International Journal of Rock Mechanics and Mining Sciences, vol. 42, no. 2, pp. 237-250, 2005.

[3] N. Erarslan, H. Alehossein, and D. J. Williams, "Tensile fracture strength of Brisbane tuff by static and cyclic loading tests," Rock Mechanics and Rock Engineering, vol. 47, no. 4, pp. 11351151, 2014.

[4] C. J. Jia, W. Y. Xu, R. B. Wang, W. Wang, J. C. Zhang, and J. Yu, "Characterization of the deformation behavior of finegrained sandstone by triaxial cyclic loading," Construction and Building Materials, vol. 162, pp. 113-123, 2018.

[5] S. J. Chen, D. W. Yin, N. Jiang, F. Wang, and Z. H. Zhao, "Mechanical properties of oil shale-coal composite samples," International Journal of Rock Mechanics and Mining Sciences, vol. 123, p. 104120, 2019.

[6] J. C. Wei, Z. C. Zhao, D. L. Zhao, Y. S. Y. Gong, and X. Wu, "Water-abundance evaluation of sandstone aquifer based on lithologic and structural charateristics," Journal of Shandong University of Science and Technology(Natural Science), vol. 39, pp. 13-23, 2020.

[7] Z. Li, H. Liu, Z. Dun, L. Ren, and J. Fang, "Grouting effect on rock fracture using shear and seepage assessment," Construction and Building Materials, vol. 242, p. 118131, 2020.

[8] Y. Wang, B. Zhang, S. H. Gao, and C. H. Li, "Investigation on the effect of freeze-thaw on fracture mode classification in marble subjected to multi-level cyclic loads," Theoretical and Applied Fracture Mechanics, vol. 111, article 102847, 2021.

[9] C. Zhu, K. Zhang, H. Cai et al., "Combined application of optical fibers and CRLD bolts to monitor deformation of a pit-inpit foundation," Advances in Civil Engineering, vol. 2019, Article ID 2572034, 16 pages, 2019. 
[10] A. R. Estabragh, M. Moghadas, and A. A. Javadi, "Effect of different types of wetting fluids on the behaviour of expansive soil during wetting and drying," Soils and Foundations, vol. 53, no. 5, pp. 617-627, 2013.

[11] E. Kalkan, "Impact of wetting-drying cycles on swelling behavior of clayey soils modified by silica fume," Applied Clay Science, vol. 52, no. 4, pp. 345-352, 2011.

[12] R. Gholami and V. Rasouli, "Mechanical and elastic properties of transversely isotropic slate," Rock Mechanics and Rock Engineering, vol. 47, no. 5, pp. 1763-1773, 2014.

[13] W. T. Salih, W. Yu, X. Q. Dong, and W. Hao, "Study on stressstrain-resistivity and microscopic mechanism of red mud waste modified by desulphurization gypsum-fly ash under drying-wetting cycles," Construction and Building Materials, vol. 249, article 118772, 2020.

[14] S. Shahsavani, A. H. Vakili, and M. Mokhberi, "The effect of wetting and drying cycles on the swelling-shrinkage behavior of the expansive soils improved by nanosilica and industrial waste," Bulletin of Engineering Geology and the Environment, vol. 79, no. 9, pp. 4765-4781, 2020.

[15] C. Zhu, X. Xu, X. Wang et al., "Experimental investigation on nonlinear flow anisotropy behavior in fracture media," Geofluids, vol. 2019, Article ID 5874849, 9 pages, 2019.

[16] H. F. Deng, Y. C. Zhang, J. L. Li, W. Wang, and Y. Y. Zhi, "Effect of moisture content on splitting tensile strength of layered sandstone," Chinese Journal of Rock Mechanics and Engineering, vol. 36, no. 11, pp. 2778-2787, 2017.

[17] Y. Inada and K. Yokota, "Some studies of low temperature rock strength," International Journal of Rock Mechanics and Mining Sciences \& Geomechanics Abstracts, vol. 21, no. 3, pp. 145-153, 1984.

[18] M. Q. You, X. L. Chen, and C. D. Su, "Brazilian splitting strengths of discs and rings of rocks in dry and saturated conditions," Chinese Journal of Rock Mechanics and Engineering, vol. 30, no. 3, pp. 464-472, 2011.

[19] Y. W. Lv, C. P. Sun, and B. T. Shen, "Experimental study on damage evolution and crack propagation characteristics of sandstone under combined stress state," Journal of Shandong University of Science and Technology(Natural Science), vol. 39, pp. 37-45, 2020.

[20] B. Vásárhelyi and P. Ván, "Influence of water content on the strength of rock," Engineering Geology, vol. 84, no. 1-2, pp. 70-74, 2006.

[21] C. Wang, Y. M. Lai, Z. M. You, Y. Yang, D. H. Yu, and G. H. Liu, "Experimental study of the effect of temperature and moisture state on rock Brazilian splitting strength," Journal of Glaciology and Geocryology, vol. 38, no. 5, pp. 1317-1324, 2016.

[22] Z. H. Zhu, P. Wu, H. Y. Yao, and D. Y. Zhu, "Split test of sandstone under conditions of cyclic saturation-drying and longterm saturation," Water Resources and Power, vol. 30, no. 12, pp. 58-60, 2012.

[23] H. F. Ma, D. W. Yin, S. J. Chen, X. Q. Liu, and B. Chen, "Research on soaking effects on the tensile strength and failure characteristics of rock," Mining Research and Development, vol. 38, no. 4, pp. 56-60, 2018.

[24] M. Wen, Z. Chen, J. Y. Xu, P. Wang, and S. H. Liu, "Staticdynamic split tensile tests and micro analysis on redsandstone with different moisture contents," Chinese Journal of Underground Space and Engineering, vol. 13, no. 1, pp. 8692, 2017.
[25] J. H. P. D. Bresser, J. L. Ural, and D. L. Olgaard, "Effect of water on the strength and microstructure of Carrara marble axially compressed at high temperature," Journal of Structural Geology, vol. 27, no. 2, pp. 265-281, 2005.

[26] C. Zhu, X. D. Xu, and W. R. Liu, "Softening damage analysis of gypsum rock with water immersion time based on laboratory experiment," IEEE Access, vol. 7, pp. 125575-125585, 2019.

[27] Z. Li, S. Liu, W. Ren, J. Fang, Q. Zhu, and Z. Dun, “Multiscale laboratory study and numerical analysis of water-weakening effect on shale," Advances in Materials Science and Engineering, vol. 2020, Article ID 5263431, 14 pages, 2020.

[28] J. Y. Zhang, L. P. Wan, H. Y. Pan, J. L. Li, Z. S. Zuo, and H. F. Deng, "Long-term stability of bank slope considering characteristics of water-rock interaction," Chinese Journal of Geotechnical Engineering, vol. 39, no. 10, pp. 1851-1858, 2017.

[29] D. F. Liu and S. Yan, "Micro-damage mechanism of sandstone fracture under coupling of hydraulic pressure and rock," Journal of Wuhan Institute of Technology, vol. 42, no. 4, pp. 439443, 2020.

[30] B. X. Huang and J. W. Liu, "The effect of loading rate on the behavior of samples composed of coal and rock," International Journal of Rock Mechanics and Mining Sciences, vol. 61, pp. 23-30, 2013.

[31] X. S. Liu, Y. L. Tan, J. G. Ning, Y. W. Lu, and Q. H. Gu, "Mechanical properties and damage constitutive model of coal in coal-rock combined body," International Journal of Rock Mechanics and Mining Sciences, vol. 110, pp. 140-150, 2018.

[32] D. W. Yin, S. J. Chen, Y. Ge, and R. Liu, "Mechanical properties of rock-coal bi-material samples with different lithologies under uniaxial loading," Journal of Materials Research and Technology, vol. 10, pp. 322-338, 2021.

[33] J. W. Cho, H. Kim, S. Jeon, and K. B. Min, "Deformation and strength anisotropy of Asan gneiss, Boryeong shale, and Yeoncheon schist," International Journal of Rock Mechanics and Mining Sciences, vol. 50, no. 2, pp. 158-169, 2012.

[34] D. Q. Dan, H. Konietzky, and M. Herbst, "Brazilian tensile strength tests on some anisotropic rocks," International Journal of Rock Mechanics and Mining Sciences, vol. 58, no. 2, pp. 1-7, 2013.

[35] A. Tavallali and A. Vervoort, "Effect of layer orientation on the failure of layered sandstone under Brazilian test conditions," International Journal of Rock Mechanics and Mining Sciences, vol. 47, no. 2, pp. 313-322, 2010.

[36] E. Q. Li, J. L. Feng, L. F. Zhang, H. C. Zhang, and T. Y. Zhang, "Investigation on Brazilian tests of layered carbonaceous Slate under conditions of water-rock interaction and weathering," Chinese Journal of Geotechnical Engineering, 2020, https:// kns.cnki.net/kcms/detail/32.1124.TU.20201027.1132.006 .html.

[37] C. Liu, C. S. Tang, B. Shi, and W. B. Suo, "Automatic quantification of crack patterns by image processing," Computers and Geosciences, vol. 57, pp. 77-80, 2013.

[38] C. Liu, B. Shi, J. Zhou, and C. S. Tang, "Quantification and characterization of microporosity by image processing, geometric measurement and statistical methods: application on SEM images of clay materials," Applied Clay Science, vol. 54, no. 1, pp. 97-106, 2011. 